\title{
La formación inicial del profesorado en el instituto-escuela: 1918-1936
}

\author{
Elías Ramírez Aisa
}

\section{INTRODUCCIÓN}

La preparación científica y pedagógica previa al ejercicio regular de la función docente ha sido tema de preocupación desde que el estado burgués comenzase a ordenar el sistema educativo; y como sigue aún requiriendo análisis y reflexión, hemos querido sacar a la luz una experiencia de formación profesional desarrollada en España entre 1918 y 1936 con el fin de servir de confrontación con los métodos actuales empleados en la formación científica y didáctica.

La cuestión es conocer cómo se organizó en el Instituto-Escuela la formación de quienes aspiraban a engrosar las cátedras de los Institutos y Escuelas Normales, asi como ver si esta experiencia tuvo continuidad a través del aparato legislativo elaborado por la Segunda República. Naturalmente, estas cuestiones han sido tratadas en linea con el contexto histórico que vivió el Instituto-Escuela.

En el primer apartado se da cuenta de lo que fue el Instituto-Escuela. Un ensayo oficial de carácter unificador entre la enseñanza primaria y secundaria como sugiere el propio titulo del nuevo centro y que, auspiciado por la Junta para Ampliación de Estudios e Investigaciones Científicas, nació con el propósito de contrastar sus experiencias y servir de modelo y laboratorio para una posible reforma de la enseñanza secundaria en España. En el segundo estudiamos el objeto en si de la investigación: el marco organizativo de los llamados en el Instituto-Escuela aspirantes al Magisterio Secundario a través del Real Decreto fundacional y Reglamento que lo desarrollaba. Todo ello completado con el tema del siguiente apartado en el que esbozamos con minuciosidad el plan de trabajo que articuló la formación recibida por los aspirantes a docentes. Cómo se asignaban grupos, la metodología seguida en la preparación de las clases, las prácticas, los cursos teóricos, la colaboración en la obra general del Instituto-Escuela,etc., 
son explicados con detalle. Los tiempos coincidentes con la Segunda República han recibido tratamiento aparte. El marco legislativo de selección y formación del profesorado puesto en marcha por el nuevo Estado democrático republicano, dada la ruptura que supone con el período precedente, justifican este apartado. Un momento histórico en el que nos hemos detenido también para preguntarnos si el ensayo de formación inicial puesto en marcha en el Instituto-Escuela, dada la proximidad ideológica entre quienes sostuvieron el Instituto-Escuela y configuraron políticamente los primeros años republicanos, sirvió para encauzar la reforma de la formación docente elaborada por la Segunda República.

No cabe duda que conviene conocer las experiencias que nos han precedido, sus coordenadas y planteamientos subyacentes; de aqui nuestra preocupación por una experiencia de formación del profesorado irrepetible, pero en la que podemos encontrar en su discurso elementos capaces de nutrir hoy nuestra reflexión. De aquí, en suma, las presentes páginas.

\section{EL INSTITUTO-ESCUELA}

Fue el 10 de mayo de 1918 cuando a través de un Real Decreto firmado por Alfonso XIII y refrendado por el entonces ministro de Instrucción Pública, Santiago Alba, nació el Instituto-Escuela. Ubicado en Madrid, nacía como ensayo pedagógico, por un período de seis años, bajo la dirección de la Junta para Ampliación de Estudios e Investigaciones Científicas.

Vio la luz en una coyuntura difícil. Si en Europa la guerra aún no había terminado, aunque se vislumbraba un final favorable para los aliados, España veía acrecentar sus problemas. Eran tiempos de violencia y de descomposición del sistema político. La industria y el proletariado crecian y con ellos la protesta social al compás de la coyuntura de beneficios que se presentó durante la primera guerra mundial para la industria española ${ }^{\dagger}$. El mecanismo de acumulación de capital fue clásico: aumentaron los precios más que los salarios nominales con lo que los salarios reales descendieron ${ }^{2}$. Ello disparó una coyuntura de beneficios y una agudización

\footnotetext{
Signo evidente de la potenciación industrial española y de las clases sociales que la protagonizan es el crecimiento urbano. Véase la distribución de la población por municipios según tamaño en Martinez Cuadrado, M.: La burguesía revolucionaria.1874-1931.Madrid, Ed. Alianza, 1973, pág. 112.

2 Sobre los mecanismo de formación de capitales y agudización de la protesta social, véase Roloan,S., Garcia Delgado, J.L. y Muñoz, J.: La consolidación del capitalismo en España. Madrid, Ed. Confederación Española de Cajas de Ahorro, 1974, Tomo II, págs. 137-266 .
} 
de la protesta social que, desde la huelga general de agosto de 1917, iba en aumento. Una protesta social que contribuirá momentáneamente a encuadrar al ejército bajo las órdenes del poder ejecutivo y a integrar en el gobierno de la nación a un sector de la burguesia de las nacionalidades con mayor desarrollo (Cataluña y País Vasco), formándose asi los llamados gobiernos de concentración en los que en su composición figuraban personalidades de otros partidos que no fueran del partido liberal y conservador. Sería con el llamado "gobierno de concentración nacional», presidido por Maura y del que formaban parte Eduardo Dato, García Prieto, Francisco Cambó y Santiago Alba, cuando nació el Instituto-Escuela. Y nacía como "un centro oficial de segunda enseñanza, donde se ensayan planes de estudio y métodos de educación que parecen adecuados a las necesidades de nuestro país" ${ }^{3}$. Estamos, por tanto, ante un ensayo que deberia servir de referente para la transformación de la enseñanza secundaria.

En su origen destacan dos fuerzas motrices. Unas profundas, que hunden sus raices en las condiciones históricas que vive la educación y en un pensamiento que, forjado en torno a la Institución Libre de Enseñanza, las revelaba. Otras inmediatas, esto es, aquellas que hacen referencia a las necesidades más perentorias asi como a las ideas y gestos de individualidades sobresalientes que impulsaron la creación del Instituto-Escuela.

A pesar del lento pero sostenido crecimiento del número de alumnos de enseñanza media en España durante la Restauración, el estado de la educación era deplorable. En 1922 no sólo existían los mismos institutos que en 1875 - !Y habían transcurrido 47 años!- , sino que, como nos revelan algunas fuentes de la época y muestran estudios actuales, la falta de atención económica era palmaria ${ }^{4}$. Situación agravada por una pedagogia que

3 Memoria. Junta para Ampliación de Estudios, años 1918-1919, Biblioteca del Consejo Superior de Investigaciones Científicas, pág. 219. En adelante, la referencia de las Memorias del Instituto Escuela, fuente primaria básica para conocer los entresijos de su vida, se citará por las siglas de la Junta para Ampliación de Estudios: JAE.

4 Ramón MACias PICAVEA, en su obra El Problema Nacional, nos muestra la situación de la enseñanza secundaria a fines del siglo XIX con estas contundentes palabras: «nuestros famosos institutos son cualquier cosa menos centros de educación y enseñanza. La mayor parte tienen por casa viejos edificios provistos de cuatro salas, tal cual pasillo o galeria y algún mediano corral abierto, o no, a la calle". Macias PICAVEA, R.: El problema nacional. Hechos, causas, remedios. Madrid, 1989, pág. 125. Ello era resultado de la parquedad de las cifras del gasto público en instrucción. El aumento del presupuesto con la creación del Ministerio de Instrucción Pública a comienzos del siglo $X X$ no fue lo suficientemente significativo como para evitar la tendencia al estancamiento. Sobre el gasto público en educación entre 1860 y 1935 remitimos al excelente trabajo de Clara Eugenia NúNEZ: La fuente de la riqueza. Educación y desarrollo económico en la España Contemporánea. Madrid, Ed. Alianza universidad,1992, págs. 288-318. En su !ugar, de la misma autora, puede consultarse el artículo titulado "El gasto público en Educación entre 1860 y 1935", 
cifraba todo su horizonte en hacer aprender de memoria todo lo que se enseñaba ${ }^{5}$.

Las pésimas condiciones materiales y pedagógicas de la segunda enseñanza — las de la primaria no son menos deplorables ${ }^{6}$ - exigian reformas que pusiesen fin a las mismas. Reformas que encontraron cauce e impulso tras la derrota del Noventa y Ocho. Pero para poner remedio era preciso disponer previamente de un pensamiento coherente capaz de vertebrar y encauzar las acciones que se pusieran en marcha para renovar y transformar la educación. Y se disponía de ese pensamiento. Se trataba de un cuerpo de ideas que siguiendo la tradición antropológica inaugurada por el Renacimiento y profundizada después por la llustración, se fue fraguando en el último tercio del siglo XIX en el sustento de la experiencia: la Institución Libre de Enseñanza. Nacida jurídicamente por un Real Decreto de 16 de agosto de 1876 como centro libre de enseñanza secundaria, en 1878 , a consecuencia de que los métodos tan novedosos que practicaba el centro serían más eficaces cuanto menor fuera la edad del alumno, se creó una sección de primaria. Así, la enseñanza secundaria sería prolongación y desarrollo de los métodos y contenidos impartidos en la sección de primaria. Su práctica pedagógica, guiada por una consideración del hombre como valor en si mismo, se basó en el método intuitivo, en el respeto a la libertad y conciencia del niño, en el gusto por el pensar y discurrir, en el cuidado del cuerpo, en la supresión de castigos, exámenes y libros de texto asi como en un férreo amor al trabajo y al esfuerzo. Un centro, por otra parte, concebido como « un pequeño ensayo que diera a la luz transformaciones susceptibles de ser generalizadas»?

en la revista Hacienda Pública Española, núm. homenaje a D. Felipe Ruiz MARTín, coordinado por F. COMin y J. ZAFRA, 1991, págs. 121-146.

5 La memorización del aprendizaje, situación normal por extendida en aquella época, nos la describe vivamente el poeta Emilio Prados, recordando su estancia en 1910 en el instituto de Málaga, antes de vivir el ambiente de libertad y provecho cultural de la Residencia de Estudiantes, con estas palabras: “...la dirección y el profesorado del Instituto Nacional de $2^{\text {a }}$ enseñanza, en Málaga, cuando comencé en él mis estudios estaba en condiciones pésimas... las clases jamás se explicaban. Solamente eran para señalar la lección que teniamos que aprender de memoria (de carrerilla, diriamos nosotros), para recitar estas lecciones por grupos". PRADOS, E.: "Notas autobiográficas", revista Litoral, № 186-187, Madrid, 1991, pág. 27.

6 Si muchas escuelas de primaria eran cuadras destartaladas, el nivel de desescolarización era elevado como muestran los datos referidos a la ciudad de Barcelona. En 1910, la enseñanza primaria oficial no cubria ni la quinta parte $(17,5 \%)$ de las necesidades escolares de la ciudad, mientras que la privada lo hace en más de 3 veces esa cifra: $56,1 \%$. Los niños sin escolarizar representan el enorme porcentaje de más de la cuarta parte de la población, número mayor que el de los que acuden a las escuelas públicas. Datos recogidos en YETANO LAGUNA, A.: La enseñanza religiosa en Barcelona durante la Restauración. Barcelona, Facultad de Letras, 1981, pág. 19.

GUERRERO SALÓN, E.: “La Institución, el sistema educativo y la educación de las clases obreras a finales de siglom, Revista de Educación, Madrid, Ed. Ministerio de Educación, 1976, N²43, pág. 71. 
La Institución Libre de Enseñanza se constituyó en el soporte ideológico y empírico que ayudó a articular y definir el proyecto de crear un Instituto-Escuela de segunda enseñanza. Los planteamientos, la orientación y los métodos pedagógicos procederán de la Institución. Los hombres que están en su origen son institucionistas. El lazo de unión es tan intimo que el historiador Tuñón de Lara considera el Instituto-Escuela y demás instituciones dependientes de la Junta para Ampliación de Estudios como la tercera y última fase de la intención reformista de la Institución Libre de Enseñanza ${ }^{8}$. Pero el que hubiera proximidad en la filosofía que orientaba la acción de ambos centros no significaba que fueron idénticos. Asi,y como se verá más adelante, en el Instituto-Escuela se siguieron los programas oficiales, catedráticos de instituto constituyeron su plantilla, se juzgaba la labor y rendimiento de los alumnos en el propio centro y se atendía a la formación del futuro profesorado.

Pero estas lineas de fuerza o causas profundas que están en el origen del Instituto-Escuela, necesitaron resortes inmediatos que lo hicieran realidad. $Y$ en este sentido hemos de señalar el ambiente deseoso de modernizar España en cierto sector intelectual así como los gestos de aquellos hombres que contribuyeron a dar forma definitiva al proyecto que fue el Instituto-Escuela.

En los años inmediatos a la creación del Instituto-Escuela se vive, por parte del sector más activo de la intelectualidad madrileña en un ambiente deseoso de renovar los mecanismos políticos y remover la marcha cultural del país, principalmente del sistema educativo. Octubre de 1913 puede ser señalado como el punto álgido de ese ambiente. En dicho mes aparece un manifiesto convocando una Liga de Educación Política. Lo firman José Ortega y Gasset, Azaña, Fernando de los Ríos... se adhieren, entre otros, Madariaga, Zulueta, Américo Castro, etc. Un ambiente impulsado por una generación que es y aspira a crear una élite capaz de remover los obstáculos que impiden modernizar a España. $Y$ en el activo de ese ambiente y grupo generacional hay que situar el Instituto-Escuela junto a otras creaciones anteriores como la Residencia de Estudiantes (1910), la Revista España (1915) o el periódico El Sol (1917). Se trata de un ambiente impulsado por una generación con vocación científica, que combate el sempiterno aislamiento internacional de España e impulsora de una nueva mentalidad cultural que aparecerá en el horizonte del pais en los años

${ }^{8}$ TUÑon de LARA,M.: Medio siglo de cultura española.1885-1936. Madrid, Ed. Tecnos, 1971, pág. 38 y 45. 
veinte y treinta. Un ambiente de neorregeneración del que participan hombres y mujeres que tendrán la responsabilidad de formar, definir y accionar el proyecto del Instituto-Escuela.

Es el caso de D. Santiago Alba, quien participando de ese ambiente neorregeneracionista e impregnado de espíritu institucionista, como hombre de élite presente en la cosa pública y dispuesto a renovar obstáculos para que España dejase de ser un problema pedagógico, siendo ministro de Instrucción Pública, dio origen al Instituto-Escuela al llevar el Real Decreto de su creación a la firma del Rey y a la Gaceta.

Al nombre de D. Santiago Alba hay que añadir la energia y el aliento permanente del que se considera padre y alma del Instituto-Escuela: D.José Castillejo Duarte. A partir de su encuentro con Giner de los Ríos ${ }^{9}$, se interesará vivamente por la educación hasta el punto de ser la pieza básica de la "última etapa de la Institución Libre de Enseñanza" ${ }^{10}$. Fue según todos los indicios redactor del Real Decreto de creación del Instituto Escuela e impulsor del mismo desde su puesto de Secretario de la Junta para Ampliación de Estudios. Un organismo que, nacido en 1907 entre reticencias políticas y escaso presupuesto, creó una estructura institucional de apoyo a la ciencia a través de estudiantes pensionados en el extranjero, programas de investigación y ensayos pedagógicos como el InstitutoEscuela. Conocedor y admirador del sistema educativo inglés, su tesis doctoral lleva por título la educación en Inglaterra, intentará que a los antecedentes y principios del sistema británico - libertad, educación moral apoyada en el cuidado estético, coeducación, no funcionarización del personal docente, formación inicial del profesorado combinando la teoria con la práctica,etc. - se ajuste el Instituto-Escuela.

Las condiciones materiales y pedagógicas de la educación en España, el pensamiento institucionista y el ambiente neorregeneracionista señalado son las razones profundas que están en el origen del Instituto-Escuela. Pero ahora cabe preguntarse: ¿quién o quiénes fraguaron el proyecto? Parece ser que primero Castillejo y María de Maeztu quisieron crear un liceo femenino y otro masculino de carácter oficial a partir de los grupos de

9 Sus biógrafos no se ponen de acuerdo respecto a la fecha de ese encuentro. Mientras Palacios Bañuelos dice que “va a ser aproximadamente en 1900, terminados sus estudios, cuando Castillejo entra en contacto con D. Francisco Giner de los Ríos", Carmela Gamero sitúa tal encuentro entre 1901 y 1902. Palacios Buñuelos, L.: Castillejo, educador. Ciudad Real, Ed. Diputación Provincial, 1986, pág. 21; GAMERo MERINo, C.: Un modelo europeo de renovación pedagógica: José Castillejo. Madrid, Ed, CSIC, 1988, pág. 23.

10 Palacios Bañuelos, L.: José Castillejo, última etapa de la Institución Libre de Enseñanza. Madrid, Ed. Narcea, 1979 
niños y niñas vinculados a la Residencia de Estudiantes ${ }^{11}$. Incluso María de Maeztu visitó a Eduardo Dato, a la sazón presidente del gobierno, con la intención de lograr la viabilidad del proyecto. Pero fracasado este plan, probablemente se pensó en un centro único que hiciese realidad la coeducación y fuese oficial a fin de salvar las dificultades que tenían los alumnos, como los de la Institución Libre de Enseñanza o grupos de niños y niñas vinculados a la Residencia, a la hora de pasar los exámenes oficiales acostumbrados como estaban a métodos activos de enseñanza. El caso es que «según cuenta Ramón Carande, la idea surgió de una conversación entre Castillejo y Cossío en la casita de los institucionistas en el Guadarrama y dice que la referencia la debe a Natalia Cossio" 12. Después, y coincidiendo con un momento favorable al ocupar la cartera de Instrucción Pública D. Santiago Alba, hombre afecto a la Institución Libre de Enseñanza, por Real Decreto de 10 de mayo de 1918 se creaba el Instituto-Escuela ${ }^{13}$. El 1 de octubre del mismo año abría sus puertas bajo la dirección de la Junta para Ampliación de Estudios. Un organismo administrativo y técnico que, actuando dentro del organigrama del Ministerio, preservaría, dado su margen de acción, del peligro de ver cercenada su libertad por la intromisión de un sistema político inestable, asi como garantizaria la necesaria continuidad en el tiempo que permitiese contrastar sus resultados. La Junta nombra al profesorado y responde ante el Ministerio de la marcha del experimento mediante mecanismos de control: memoria bienal, memoria balance de los resultados obtenidos a los seis años de funcionamiento ${ }^{14} \mathrm{y}$, como dice el Real Decreto, con cuantas «resoluciones que deban adoptarse para la reforma y propagación de los nuevos métodos de enseñanza a los demás establecimientos oficiales". La Junta inspecciona de modo permanente el Instituto-Escuela, aunque estas

1 En 1914 se puso en marcha una Residencia para nin̄os menores de diecisiete años aneja a la Residencia de Estudiantes. Concebida como ensayo, se trataba de hacer compatible los métodos intuitivos y el programa de estudios oficial, al tiempo que se incluian clases de dibujo, trabajos manuales, deportes, prácticas de laboratorio, etc. Dos años después, en 1916, la Junta para Ampliación de Estudios dio autorización para abrir una residencia de niñas entre 6 y 11 años. Ambos grupos, el de niños y niñas, son considerados como los embriones del futuro InstitutoEscuela.

12 TERAN, M. DE: «El Instituto Escuela y sus relaciones con la Junta para Ampliación de Estudios y la Institución Libre de Enseñanza". En el centenario de la Institución libre de Enseñanza. Madrid, Ed. Tecnos 1976, pág. 194.

13 El texto integro del Real Decreto en Historia de la Educación en España. De la Restauración a la I/ República. Madrid, Ed. Ministerio de Educación y Ciencia, 1989, págs. 197-204.

${ }^{14}$ La memoria balance, fuente indispensable para conocer el Instituto-Escuela, se publicó con el título de Un ensayo Pedagógico. El Instituto Escuela de Segunda Enseñanza de Madrid (organización, métodos, resultados). Madrid, JAE, 1925. 
inspecciones "se convirtieron en estímulo, en cambio de impresiones o incluso en discusión. Fue una cooperación bien aceptada, quizá porque se hacía con respeto, como ayuda al profesorado en su labor y, de hecho, estas inspecciones no rompieron el espíritu de concordia que reina en el Instituto Escuela» ${ }^{15}$.

Nacido con un claro sentido unificador, hasta el punto que está sugerido en el propio nombre de Instituto-Escuela ${ }^{16}$, el ensayo debería contrastar y tomar como objeto de reflexión «la cuestión del Bachillerato único o múltiple, los planes de estudio; los métodos y prácticas de enseñanza de cada rama, el sistema de promoción de los alumnos de un grado a otro, que toca de lleno al problema de los exámenes; la acción educativa y el influjo moral sobre los niños; la formación del carácter, la cooperación entre la familia y la escuela; las relaciones entre la escuela y el medio social, los deportes, ejercicios físicos y problemas de higiene y tantos otros" ${ }^{17}$.

Como toda buena esperanza ha de fundarse en la preparación del personal docente, el Instituto-Escuela fue también un centro de ensayo para futuros profesores de enseñanza secundaria. Con el apelativo de aspirantes al magisterio secundario, acogía a jóvenes que tuvieran título de magisterio o estudios universitarios durante dos años, enviando posteriormente pensionados al extranjero a los que obtuvieran mayor provecho. La formación de dichos aspirantes, esbozada en el artículo 11 del Real Decreto de fundación y desarrollado a través de unas instrucciones ${ }^{18}$, combinaba simultáneamente las prácticas docentes en el Instituto-Escuela, la preparación científica en los laboratorios de que dispuso la Junta, enseñanza de idiomas, asistencia a clases en la Universidad, lecturas personales y colaboración en la obra educativa del Instituto-Escuela.

Las enseñanzas se organizaron en dos bloques. Cada uno se repartía en tres grados de preparatoria que acogía a niños de ocho a diez años y seis grados de bachillerato con alumnos entre once y dieciséis años. El

15 OntAÑon, E.: «El Instituto Escuela, experiencia educativas de la Junta para Ampliación de Estudios", en Junta para Ampliación de Estudios e Investigaciones Científicas 80 años después. Simposio internacional, Madrid, 15-17 diciembre de 1987, Madrid, Ed. CSIC, 1988, vol. 2, pág. 223.

16 Oue el nombre haga alusión al carácter unificado de sus enseñanzas es puesto en duda por Palacios Bañuelos. Dicho autor sostiene que la palabra escuela hace referencia, en el sentido de escuela profesional, a la formación del futuro profesorado. Palacios Banuetos, L.: Instituto Escuela. Historia de una renovación pedagógica. Madrid, Ed. Ministerio de Educación y Ciencia, 1988, pág. 39.

7 Real Decreto de 10 de mayo de 1918, en Historia de la Educación en España, op. cit., pág. 198

18 Memoria. JAE, 1918-1919, págs. 252-255. 
plan de estudios, detallado en el Reglamento que con fecha de 10 de julio de 1919 se publicó en la Gaceta, recoge los fundamentos que ya orientaron la Institución Libre de Enseñanza ${ }^{19}$, aunque con la diferencia de estar ajustados a los planes oficiales. Dos son las ideas que lo inspiran: de un lado, se trata de ofrecer una cultura general, impartida de forma cíclica, esto es, repitiendo y profundizando la misma materia cada año; de otro, se concede cierto margen de elección al alumno en función de su aptitud, criterios familiares y consejo del profesorado. El plan de estudios quedó fijado en:

a) Estudios comunes para todos los alumnos: lenguas vivas (francés, inglés o alemán), filosofía, dibujo y música.

b) Estudios de materias comunes impartidas con diferente intensidad según fueran o no base de especialización : Matemáticas, Física y Química, Ciencias Naturales, Lengua y Literatura, Geografía e Historia.

c) Asignaturas de Letras: Latin y Griego.

Al igual que se hiciera en la Institución, se introdujeron asignaturas teóricas como carpintería o encuadernación y se puso en práctica «el símbolo de los métodos educativos de la Institución Libre de Enseñanza: las excursiones" ${ }^{20}$. Se suprimieron los exámenes y los libros de texto. Resúmenes, lecturas, resoluciones de problemas, prácticas de laboratorio, etc. se constituyeron en los indicadores de que se servian los profesores para estimar la labor de los alumnos. Una estimación que, a pesar de la ausencia de exámenes, se mostró rigurosa: en 1924 sólo obtuvieron el titulo de bachiller 27 alumnos de los 87 que ingresaron en $1918^{21}$. Tampoco encajaba en la pedagogia del Instituto-Escuela la separación de sexos. No obstante, la coeducación se practicó con dificultad debido a la separación de locales ${ }^{22}$.

19 Una muestra de las semejanzas metodológicas y pedagógicas entre el Instituto-Escuela y la Institución Libre de Enseñanza lo demuestra el informe que redactó esta última, en 1919, a petición del Consejo de instrucción Pública, sobre la reforma de la enseñanza secundaria. La coincidencia en el diagnóstico y en las propuestas con el plan de estudios y pedagogía iniciado en el Instituto-Escuela es casi total. El informe, publicado en el Boletin de la Institución Libre de Enseñanza de 1919, fue nuevamente editado por la Revista de Educación en 1975 . Véase "Informe de la Institución Libre de Enseñanza sobre la segunda enseñanza y su reformas, Revista de Educacion, año XXIII n ${ }^{\circ} 238$, mayo-junio, 1975, págs. 110-119.

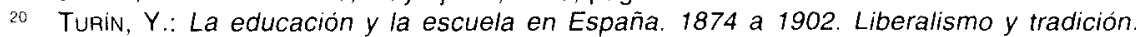
Madrid, Ed. Aguilar, 1967, págs. 204

21 Un ensayo pedagógico, op. cit, pág. 109. Los datos de aprobados, junto a la extracción social del alumnado, desmienten el carácter popular que el sociólogo Esteban Medina atribuyó al Instituto-Escuela. Medina, E.: Educación y Sociedad. Madrid, Ed. Ayuso, 1975, pág. 85.

22 El Instituto-Escuela inició su andadura en los locales del International institute for Girls in Spain, en las calles madrileñas de Miguel Angel 8 y Fortuny 53 . Pero como la norma de este 
En 1930, dos meses después de la dimisión del general Primo de Rivera, y siendo Ministro de Instrucción Pública D. Elias Tormo, por un Real Decreto con fecha de 1 de marzo, el Instituto Escuela consolidaba su situación al adquirir el carácter de permanente. Poco después, con el advenimiento de la Segunda República, tiempos de bonanza se presentaron. Aceptada la validez del ensayo, la República procedería a autorizar tres institutos concebidos a la manera del Instituto-Escuela en Barcelona y a crear uno en Sevilla, Valencia y Málaga respectivamente.

La guerra civil quebrará definitivamente la vida del Instituto-Escuela. Sus edificios serían incautados y su profesorado postergado, salvo alguna excepción, al silencio y el exilio. Una experiencia que si bien en vida ya tuvo una influencia reducida, tras la guerra civil quedaría arrancada de la memoria colectiva, aunque sorprendentemente, en 1970 seria recordada por la via de un descarado parafraseo del Real Decreto de creación y memoria balance de 1925 en la Ley General de Educación ${ }^{23}$. Es cierto que el discurso que sostuvo aquella experiencia de dieciocho años es ya irrepetible, pero no lo es menos que aún conserva una sabiduria que puede contribuir a abrir nuevos y enriquecedores puntos de inserción con el presente educativo.

\section{ASPIRANTES AL MAGISTERIO SECUNDARIO}

El tema de la formación docente en la segunda enseñanza venía preocupando a la Junta para Ampliación de Estudios ${ }^{24}$. En la memoria de

instituto era que en sus locales sólo estudiasen niñas, a partir del curso 1919-1920 pasaron los nin̄os del Instituto-Escuela a un pabellón de la calle Pinar, impidiéndose hasta la construcción del actual instituto Isabel la Católica de Madrid en 1928 la continuación de la tarea coeducadora.

${ }^{23}$ Vèase LAPORTA, F.J. y ZaPATERO, V.: “¿Por qué los jóvenes de hoy sin institución?", En el centenario de la institución, op .cit., págs. 221-239. Ambos autores ofrecen una lectura paralela de fragmentos de la memoria del Instituto-Escuela de 1925 y Real Decreto de creación por una parte, y la Ley General de Educación, en su exposición de motivos, por otra. La copia es a veces tan literal que los autores, con negra ironia, llegan a afirmar que "del fusilamiento de las personas se está pasando al fusilamiento de los textos".

${ }^{24}$ La preocupación no era nueva, pues en 1909 la Junta para Ampliación de Estudios creó un centro para dar nuevo impulso a la formación del magisterio: La Escuela de Estudios Superiores del Magisterio. Fue una escuela de élite que tuvo la pretensión de preparar de modo sólido, tanto desde el punto de vista científico como cultural, a quienes tendrian la responsabilidad de formar al futuro magisterio o, desde la inspección de la enserianza primaria, tuviera misiones de control y orientación educativa. La Escuela Superior del Magisterio, a la que accedieron muchos de los jóvenes que se formaron en el Instituto-Escuela, fue suprimida por la II República. Véase MOLERO Pintado, A. y DEl Pozo Andrés, M. del Mar (eds.): Un precedente histórico en la Formación Universitaria del profesorado español. Escuela de Estudios Superiores del Magisterio (1902-1932). Departamento de Educación, Universidad de Alcalá, Madrid, 1989 
1912-1913 se nos informa de que "se echaban en falta solicitudes de profesores de segunda enseñanza sobre temas pedagógicos» 25. En 1917 llegó la Junta a incluir en la convocatoria de pensiones el siguiente apartado: "desearia la Junta conceder algunas pensiones para hacer en Universidades y escuelas Nacionales Superiores estudios y prácticas adecuadas a la preparación del profesorado de segunda enseñanza» ${ }^{26}$. Dado el fracaso de estas invitaciones, la Junta se decidió por incluir, dentro del ensayo de reforma de la segunda enseñanza que representaba el InstitutoEscuela, la formación de los futuros enseñantes haciendo de ello uno de los aspectos originales del nuevo centro.

Exigia el artículo 10 de su Real Decreto fundacional que los aspirantes fueran jóvenes con diecisiete años cumplidos y que hubieran acabado o estuvieran cursando estudios universitarios en las Facultades de Ciencias o Letras. Por otra parte, entre los criterios de admisión, la Junta tenía en cuenta si habian publicado algún trabajo o hubieran tenido relación con la Junta, bien como becarios o a través de la Residencia de Estudiantes. Asi, el Instituto-Escuela se convirtió en una escuela práctica para un corto número de estudiantes maestros o licenciados que deseaban dedicarse a la docencia. Desde luego, en el Instituto Escuela se puso especial empeño en la formación de estos jóvenes que no tenían experiencia educativa y que serian más permeables a los ideales de las nuevas maneras de educar que se querían transmitir.

Cada año, conforme al articulo 42 del Reglamento del Instituto-Escuela ${ }^{27}$, sólo se admitían un número limitado de alumnos a fin de hacer efectivas las prácticas. Alumnos que " dirigirían sus peticiones a la Junta, expresando: edad, estudios y prácticas de enseñanza realizadas con anterioridad y centros donde se hicieron; publicaciones, trabajos, inéditos o notas de estudio; lecturas o experimentos que puedan aducir, y especialidad a que desean dedicarse" ${ }^{28}$. Admitidos los alumnos se distribuian por especialidades o secciones que agrupaban materias homogéneas bajo la dirección de un profesor catedrático designado por la Junta. Las secciones, tal y como prescribia el precepto 45 del citado Reglamento, fueron:

\footnotetext{
25 Cit. en Laporta, F.J.;Ruiz Miguel, A.; Zapatero, V. y Solana, J.: “Origenes culturales de la Junta para Ampliación de Estudios", Revista Arbor, julio-agosto, Madrid, 1987, pág. 45.

26 Memoria. JAE, 1916-1917, pág. 13.

27 Una copia del Reglamento se encuentra en PALAcios Bañuelos, L.: El Instituto-Escuela, op. cit., págs. 285-298. Dicho Reglamento fue elaborado, como desarrollo del Real Decreto de 10 de julio de 1918, a propuesta de la Junta para Ampliación de Estudios.
}

28. Ibidem, pág. 296. 
1. Sección preparatoria, con todos sus estudios elementales.

2. Lengua y Literatura castellana y lenguas y literaturas modernas.

3. Geografía política e Historia

4. Psicología, lógica, ética, derecho y estudios sociales filosóficos.

5. Matemáticas

6. Ciencias Físico-químicas

7. Ciencias Naturales, Fisiologia, Higiene y Agricultura.

8. Lenguas y literatura clásicas

9. Trabajos manuales y artísticos.

Pero la falta de personal suficiente para dirigir la formación de los aspirantes, hizo que se abriese el curso 1918-1919 con sólo cuatro secciones de las nueve preceptuadas: la sección preparatoria dirigida por Maria de Maeztu, la de lengua y literatura dirigida por el ya catedrático de la Universidad Central D. Ramón Menéndez Pidal y la de Matemáticas y Ciencias Naturales dirigidas respectivamente por D. Julio Rey Pastor e Ignacio Bolivar. Todos catedráticos universitarios de notable prestigio y que ninguna retribución percibieron por el desempeño de esta función. Será para el curso 1920-1921 cuando se añadan las secciones de Geografía e Historia, Física y Química y Lengua y Literaturas Clásicas. Todas coordinadas por D. Martín Navarro Flores, catedrático de Psicología, Lógica y Ética en el Instituto de Tarragona y que en 1920 fue agregado al Instituto-Escuela como responsable de la orientación filosófica asi como del desarrollo del programa de formación de los aspirantes del magisterio secundario, nombre con que genéricamente se conocía a los jóvenes que en el Instituto-Escuela se preparaban para la función docente. En 1925 Martín Navarro seria sustituido por Luis Zulueta quien a partir de ese año se encargaría de la formación pedagógica de los aspirantes al Magisterio Secundario hasta 1932 en que sus cargos como diputado a Cortes, primero, y de ministro, después, le impidieron seguir realizando tal cometido. La Junta no nombró sustituto con lo que los profesores, en su labor diaria, suplieron la tarea de coordinador que venia desempeñando D. Luis Zulueta.

\section{EL PLAN DE TRABAJO}

El plan de trabajo,esbozado en el art. 11 del Real Decreto de creación del Instituto-Escuela, lo desarrolló la Junta en unas instrucciones que 
serán incluidas en la memoria del curso $1918-1919{ }^{29}$. La preparación tenia dos fases: una en España, en el Instituto-Escuela durante dos años, y otra, en el extranjero, donde se enviarian pensionados por la propia Junta a aquellos alumnos que demostraran actitudes, interés y provecho. A fin de que el plan diera el mayor rendimiento se prohibía a los alumnos que compatibilizaran sus estudios en el Instituto-Escuela con cualquier otra ocupación. Una prohibición lógica para favorecer que los aspirantes dedicasen todo su esfuerzo a su formación, aunque fue uno de los obstáculos con que tropezó el programa de formación como se reconoció en la memoria balance $2^{30} \mathrm{El}$ programa de formación de los aspirantes al Magisterio Secundario se articuló del siguiente modo :

1. Prácticas en el Instituto-Escuela. Se procuró que éstas fueran desarrolladas por la mañana o bien durante la tarde, quedando el resto del dia, en función del horario, libre para la realización de otras actividades preparatorias. Las prácticas se subdividían en:

a) Prácticas en sentido estricto, esto es, el aspirante impartía clases a un grupo de alumnos dentro de su especialidad, pues se le asignaba un grupo concreto a lo largo del curso. Asi se trataba de evitar que el carácter auxiliar de su función sólo sirviera para cubrir ausencias al tiempo que permitia ofrecerle un medio que estimulara su iniciativa y responsabilidad. Las clases del aspirante debían estar debidamente preparadas. A tal fin se le exigía lo que hoy suele denominarse como programación, esto es, un plan que desarrollase el contenido y metodología a desplegar en el grupo asignado. Dado que la improvisación estaba desterrada del InstitutoEscuela, el Plan a desarrollar por el aspirante debía contener:

- Una delimitación de la materia que iba a impartir desarrollándola en un programa o cuestionario en el que se fijarian los fines que se pretendian alcanzar dentro de un cronograma del tiempo disponible.

- La metodología que se iba a impartir junto a unos recursos que debían estar orientados a despertar el interés y curiosidad de los alumnos.

Este esquema debería ser completado con observaciones sobre el resultado obtenido. Todo un anticipo de ese concepto tan habitual en los medios escolares actuales como es el de la autoevaluación docente.

29 "Instrucciones y consejos para los aspirantes al magisterio secundario". Memoria. JAE, curso 1918-1919, págs. 252-255.

30 "La angustia económica, se dice en la memoria, de la gran mayoria de licenciados en Ciencias y Letras, que necesitan, desde que salen de la universidad, y aún antes, ganarse su vida, y no pueden dedicar todo su esfuerzo a completar su formación". Un ensayo pedagógico, op. cit., pág. 396. 
Teniendo en cuenta que el empleo de los aspirantes como sustitutos de profesores ausentes sólo se dio en casos de urgencia e inevitables, el programa se desarrollaba ante el curso que tuvieran asignado y de modo continuo, procurando, siempre que se pudo, que los más antiguos y experimentados se encargaran de las clases y se les confiara más horas. Era la manera de que las prácticas se desarrollaran por un sendero de eficacia y responsabilidad. Unas prácticas que durante el curso 19241925 se intensificaron en sus aspectos de análisis y discusión al darse clases tanto en presencia de sus profesores como compañeros aspirantes, quienes «reuniéndose luego, estudiaban con el interesado la labor pedagógica realizada y discutían, a propósito de estos casos concretos, los problemas de la enseñanza planteados en el Instituto, buscando asi la mejora de la obra común" ${ }^{31}$. Por tanto, métodos, programas y dificultades encontradas en la realización docente eran discutidas en clases dedicadas a este fin para asi pulir la preparación científica y didáctica de los aspirantes.

b) Colaboración, junto al resto del profesorado, en todos los ámbitos y aspectos que constituían la vida entera del Instituto-Escuela: disciplina, orden, excursiones, juegos, patios, etc. Aspectos que forman parte de la vida diaria del centro y que los aspirantes dado su carácter educativo debían igualmente aprender. Una colaboración en la que, en comunión con la Institución Libre de Enseñanza, sirvió para inculcar la necesidad de cuidar la estética para elevarla al plano moral: "una ropa manchada, una cara sin afeitar, revelando pereza o despreocupación; una frase de mal gusto, un ademán de ira, quitan de tal modo autoridad ante la mirada penetrante (aunque generalmente irreflexiva) de los niños, que acarrean a veces el fracaso de un maestro,cualquiera que sea su ciencia y laboriosidad" 32 . Los aspirantes, como los catedráticos y maestros, no se limitan a impartir clases y corregir trabajos escritos, sino que " vigilan en galerías y campos de juego; establecen guardias por turno para prever la ausencia de algún compañero y sustituirlo; se encargan de mantener el orden y velar por los buenos modales, la cortesia y moderación de los niños; acompañan a estos a las excursiones" ${ }^{33}$. En suma, participan de todas aquellas funciones que tienen un valor educativo y un influjo en la formación moral y del carácter de los muchachos, lo que llevaba a completar el saber de la especialidad científica con el espacio de la ética.

31 Memoria. JAE, 1924-1925, pág. 388.

32 Memoria. JAE, 1918-1919, pág. 253

33 Memoria. JAE, 1920-1921, pág. 261. 
2. Participación científica del aspirante en la especialidad elegida. Aprovechando los medios de que disponía la Junta para Ampliación de Estudios - Centro de Estudios Históricos, Laboratorio Matemático, de Ciencias Naturales y de Investigaciones Físicas y Químicas-, y bajo el consejo y guía de los catedráticos respectivos, los aspirantes, mediante la participación en investigaciones desarrolladas en dichos laboratorios, incrementaban su preparación científica. Además de poder participar en las investigaciones que estuvieran en curso, a cada aspirante se le asignaba un tema o una serie de problemas para que trabajase personalmente. Este trabajo de Laboratorio era completado con lecturas gracias a los libros y revistas facilitados por los propios laboratorios o el Centro de Estudios Históricos

3. Como es lógico, la preparación científica quedaba completada con la pedagógica y filosófica. Una preparación organizada en torno a:

a) Asistencia a clases de Filosofía y Pedagogía en la Universidad Central y en la Escuela de Estudios Superiores del Magisterio, donde eran admitidos aquellos aspirantes que lo solicitaban.

b) Asistencia a las clases que se daban en el propio Instituto-Escuela y que posteriormente servirían de viva discusión sobre la idoneidad de los métodos, asi como las conferencias organizadas en el propio InstitutoEscuela, primero a cargo de Maria de Maeztu y luego con Navarro Flores.

c) Lectura de libros sobre educación, filosofía y psicología bajo la dirección de los profesores encargados y para lo cual se organizaban reuniones especificas para el comentario de las mismos y debate de sus dudas.

4. Todo aspirante tenía la obligación de aprender dos idiomas: francés, inglés o alemán. Se enseñaban en el propio Instituto-Escuela por profesores nativos. Todo este detallado plan se completaba con la posibilidad de obtener beca en el extranjero. Concedida por la Junta, sólo alcanzaban la pensión aquellos alumnos que hubieran demostrado tener aptitudes junto a un apreciable rendimiento durante su estadía de dos años en el Instituto-Escuela ${ }^{34}$.

Los aspirantes recibian una remuneración, aunque escasa, por sus estudios y trabajos. Durante el curso 1918-1919 se les concedió retribuciones que oscilaban entre 60 y 200 pesetas mensuales durante los nueve

34 Sobre quienes fueron becados y su influencia en la pedagogia y ciencia española, véase MARIN ACED, T.: La renovación pedagógica en España (1907-1936). Los pensionados en Pedagogia por la Junta para Ampliación de Estudios. Madrid. Ed. CSIC, 1990. 
meses del curso. Dado que no había dinero para todos, las becas retribuidas solian recaer en aquellos que cursaban el segundo año y además tenían un curso a su cargo. En 1922 hubo un cambio en el tema de las retribuciones, estableciendo la Junta los siguientes criterios:

- las primeras seis horas semanales de clase encargada se retribuían con beca mensual a 3,50 pesetas/hora.

- si se daban más de seis horas semanales podía aumentarse la beca abonando la hora que excediese de esas seis horas y no pasase de doce a razón de 2,50 pesetas.

- las horas de clase que excedían de doce horas y las horas en las que los aspirantes eran, además, encargados de guardias u otras labores, se calculaban a 2 pesetas máximo.

El mayor número de horas solía asignarse a los alumnos de mayor antigüedad o mejor preparación. Un sistema de pago que a la Junta no le parece el más adecuado porque «tiende a sugerir al profesor la falsa idea de que su misión queda encuadrada en los límites estrictos de su horario, cuando acaso su labor más valiosa sea la que pueda realizar fuera de él con su cooperación espontánea, no tasada, y su constante interés por la obra común" ${ }^{35}$. A pesar de este juicio tan próximo a ese tono misionero laico tan querido por los institucionistas, al curso siguiente se incrementarian las remuneraciones a los aspirantes al Magisterio. Era el reconocimiento a la sobrecarga educadora que, debido a la escasez de maestros y catedráticos en el Instituto-Escuela, se confiaba a los aspirantes.

Por otra parte, en alguna ocasión los aspirantes plantearon el deseo de ingresar en la plantilla del Instituto-Escuela. Una petición que dislocaba de raiz los ideales que sustentaban al Instituto-Escuela. El InstitutoEscuela, no lo olvidemos, era un espacio de formación de profesores que luego integrarian las filas de los docentes de la enseñanza secundaria principalmente y, por tanto, su estancia en el Instituto era meramente provisional. $Y$ no sólo chocaba con la filosofía originaria del Instituto, sino también con el pensamiento de la Junta para Ampliación y de su Secretario, José Castillejo, nada proclive a funcionarizar al personal del Instituto-Escuela, pues, temía que de hacer funcionarios a los miembros del Instituto-Escuela, con el tiempo y el peso de las tradiciones, se arrumbaria el entusiasmo de un ensayo que debia estar permanentemente abierto a la renovación. De hecho, cuando Elias Tormo, por Real Decreto

35 Memoria, JAE, 1926-1927, pág. 305. 
de 1 de marzo de 1930 otorgó al Instituto-Escuela carácter permanente, los catedráticos no serían nombrados titulares hasta haber desempeñado tres años la función docente, y lo serian cuando su rendimiento se considerase satisfactorio. Y aún asi, en todo momento "la Junta para Ampliación de Estudios, asesorada por la Comisión del Patronato y por el Claustro del Instituto Escuela, podía separar de su cargo a un catedrático cuando no se halle identificado con los métodos seguidos en este centro de ensayos pedagógicos" ${ }^{36}$. En este caso el catedrático quedaría en excedencia forzosa y con dos años para elegir vacante. En consecuencia, si se establecieron mecanismos que evitasen la funcionarización de los catedráticos titulares, era lógico que se evitase, a pesar de las presiones que hubo, que los aspirantes al magisterio ocupasen plaza definitiva en el Instituto-Escuela. Y ello por dos razones en opinión de la Junta: " a) porque eso prostituiría la función del Instituto-Escuela, sustituyendo el interés de formarse por el de obtener un puesto, y el deseo de solidez por el de rapidez; b) porque tenderá a formar un cuerpo de aspirantes por antigüedad de escalafón, pronto repleto, siendo obstáculo para el avance de los mejores" ${ }^{37}$. A pesar de los obstáculos para que los aspirantes al magisterio ingresaran en 23 plantilla, hubo algunos casos, y fueron excepcionales, los que pudieron quedarse en el Instituto-Escuela y pasar de aspirantes a profesores adjuntos. Manuel Terán, Pedro Moles, César Arias y pocos más fueron las excepciones.

\section{EN TIEMPOS DE LA SEGUNDA REPÚBLICA}

La incapacidad de la Dictadura de Primo de Rivera para contener las aspiraciones de los nuevos grupos sociales, obreros y clases medias urbanas, cada vez más organizadas en sindicatos y con reivindicaciones programáticas más precisas, están en el origen del advenimiento de la Segunda República en la memorable jornada del 14 de abril de 1931. Nacía un nuevo sistema político deseoso de pulir injusticias y poner en sintonía al país con el capitalismo contemporáneo. $Y$ entre los muchos problemas a abordar está la educación, piedra angular para asentar una nueva ideología democrática.

Entre los primeros decretos del Ministerio de Instrucción Pública está el de 3 de julio de 1931 sobre selección del Magisterio. No se refiere a las

\footnotetext{
36 Memoria, JAE, 1929-1930, págs. 353-354
}

37 Un ensayo pedagógico, op. cit., pág. 395. 
Escuelas Normales, pero tiene relación con ellas en la medida en que se suprimen las oposiciones: " el ingreso en el ejercicio del Magisterio primario nacional se verificará mediante cursillos de selección profesional» 38 . Estos cursillos, de acuerdo a su título $3^{\circ}$, quedaban divididos en tres partes: clases en las Escuelas Normales, prácticas de enseñanza en las escuelas de primaria y preparación cultural en la Universidad. Como afirma Mariano Pérez Galán: “con ello se abarcaban los tres aspectos esenciales de la preparación exigible a un maestro: cultura general, preparación pedagógica y práctica profesional» ${ }^{39}$. Esta reforma se completaba con el decreto de 29 de septiembre de 1931 y que provocó un cambio profundo en la formación del magisterio. Un cambio que venía justificado en su preámbulo con estas palabras: "El primer deber de toda democracia es este: resolver plenamente el problema de la instrucción pública...pero siendo en la instrucción primaria el primer factor el maestro, toda la fuerza de la reforma se frustraría sin un maestro que la encarnara en su espíritu. Urgía crear escuelas, pero urgía más crear maestros; urgía dotar a la escuela de los medios necesarios para que cumpliera la función social que le está encomendada, pero urgía más capacitar al maestro para convertirlo en sacerdote de esta función; urgía elevar la jerarquía de la Escuela, pero urgía igualmente dar al maestro de la nueva sociedad democrática la jerarquía que merece y merecerá haciéndole merecedor de ella» ${ }^{40}$. Para ello se exigía el título de bachiller para acceder a las pruebas de ingreso de la Escuela Normal. Tres años de estudio y un conjunto de enseñanzas especiales - párvulos, educación física, arte, etc.- completaban lo que hoy suele denominarse curriculum. Tras finalizar el examen del conjunto de las enseñanzas recibidas, los alumnos iniciaban el período de prácticas docentes, donde ya percibian haberes. Los aprobados ingresaban directamente en el escalafón del Estado con el sueldo de 4.000 pesetas al año. Aunque el Decreto, según muestra Pérez Galán ${ }^{41}$, fue recibido con posturas divergentes, se iniciaba una nueva andadura que durante el período radical-cedista recibiría los embates de signos legislativos contrarios. No cabe duda que, inscrito en el relevante papel concedido por la República de primera hora a la cultura, se trataba de ensanchar la formación integral del maestro.

\footnotetext{
38 Decreto de 3 de julio de 1931. En Historia de la Educación en España. La ll República. Textos y Documentos. Vol. IV, Madrid, Ed. Ministerio de Educación y Ciencia, 1991, pág. 147.

39 Pérez Galán, M.: La enseñanza en la Segunda República. Madrid, Ed. Cuadernos para el Diálogo, 1973, pág. 52

40 En Historia de la Educación en España. La I/ República. Vol. IV op. cit., págs. 54-55

41 Pérez Galan, M.: op. cit., pág. 54-55.
} 
La formación del profesorado de secundaria sería canalizada a través de la Sección de Pedagogía creada en 1933 en la facultad de Filosofía y Letras. Sustituyó a la que fuera semillero de Inspectores y profesores de Escuela Normal: la Escuela de Estudios Superiores del Magisterio. Con esta sección de pedagogia se inauguraba una linea de preparación de los docentes de secundaria continuada en 1970 y $1990^{42}$ al habilitar el Certificado de Estudios Pedagógicos, tras un curso de un año de duración, a los licenciados en Filosofía y Letras y en Ciencias que quisieran opositar a cátedras de Instituto o Escuelas Normales. Por otra parte, el Decreto de creación de esta sección de pedagogía conexionaba al profesorado de Escuelas Normales y Maestros con la universidad, un objetivo largamente acariciado por los hombres de la Institución Libre de Enseñanza.

A pesar de las innovaciones legislativas introducidas por la Segunda República y que obligaban al Instituto-Escuela por ser un centro oficial, apenas hubo modificaciones en la formación de los aspirantes al magisterio secundario. Así, aunque en la Sección de Pedagogia se creaba un curso de un año para formar didácticamente a los futuros profesores de secundaria, el Instituto-Escuela continuó con su originario programa de formación. No obstante, previo informe de las Juntas de profesores y a propuesta del Comité del Patronato, el Ministerio agregó a 14 profesoras encargadas de curso y que procedían del curso de selección realizado antes del verano de 1933. Todas ellas aspiraban a ser maestras. A pesar de que originalmente la preparación pedagógica se localizó en el profesorado de secundaria, fue la sección de preparatoria la que mejor se adaptó a la nueva legislación. De todas las maneras en el Instituto Escuela las cosas siguieron igual, mostrando una clara contradicción con las nuevas realidades administrativas sobre formación inicial del profesorado puestas en marcha por el nuevo estado democrático. Así, la última memoria de la Junta, la correspondiente al curso 1933-1934, seguía registrando 68 personas, entre hombres y mujeres, como aspirantes al magisterio secundario.

Llegados a este punto cabe preguntarse por esta experiencia, de si la misma tuvo continuidad o si, dada la proximidad ideológica entre quienes sostuvieron el Instituto Escuela y conformaron políticamente los primeros

\footnotetext{
42 En la Ley General de Educación de 1970, en su artículo 102.2 se estableció que el profesorado obtendria una formación pedagógica a cargo de los Institutos de Ciencias de la Educación. En la más reciente Ley Orgánica General del Sistema Educativo (LOGSE), en su artículo 24.2 se establece que para impartir las enseñanzas en Secundaria Obligatoria y Bachillerato, así como Formación Profesional, se deberá estar en posesión de un título de especialización didáctica. Véanse ambas leyes en el Boletín Oficial del Estado de 6 de agosto de 1970 y 4 de octubre de 1990 respectivamente.
} 
años republicanos, sirvió de referente para encauzar la reforma de la formación docente elaborada por la República. En nuestra opinión, más allá de la coincidencia unánime de que toda formación docente ha de ser profesional y práctica en el ver y enseñar, no encontramos que la experiencia de formación inicial que se ensayó en el Instituto-Escuela fuera continuada ni sirviera de referente para elaborar el marco legislativo republicano. Un plan de dos años, encargándose de las clases directamente los aspirantes junto a la labor investigadora en laboratorios y asistencia a clases en la universidad, además de aprender dos idiomas y con la posibilidad de ser becado en el extranjero, constituyó entonces, y aún hoy, un programa de formación inicial excepcional y de élite. Un programa del que sólo encontramos un atisbo de semejanza en la filosofía pero no en la concreción y desarrollo de la legislación puesta en marcha por la República. La coincidencia abarcó a los tres aspectos básicos de la formación docente - cultura general, preparación pedagógica y práctica profesional--, pero no al modo de materializar dichas lineas de trabajo. Tampoco la creación de un certificado de estudios pedagógicos en la Sección de Pedagogia de la Facultad de Filosofía y Letras estaba en la linea de lo desarrollado en el Instituto-Escuela. La recomendación de la Junta para Ampliación de Estudios en 1925 de que "debería dictarse una disposición general exigiendo a quienes pretenden hacer oposiciones o ingresar de otro modo en el profesorado secundario, las prácticas de enseñanza y laboratorio y los conocimientos filosóficos y de lengua que quedan enumerados y señalando las condiciones y los centros donde deba hacerse esa preparación ${ }^{43}$, no tuvo extensión ni continuidad ni en los tiempos de la Segunda República ni, por supuesto, tras la guerra civil.

La formación inicial del profesorado ensayada en el Instituto-Escuela, no sólo fue una solución económica al evitar engrosar la plantilla de catedráticos o profesores adjuntos del propio Instituto-Escuela, sino, sobre todo, un medio de contribuir a la formación y selección de los más capacitados, raíz de una buena enseñanza y más si se pretende reformarla e introducir novedades difícilmente de ser asumidas por un profesorado acomodado a las inercias de la mera tradición. Constituyó una experiencia irrepetible de la que obtuvieron provecho cultural y profesional los propios aspirantes, pues muchos de ellos, dado el nivel selectivo y de exigencia del Instituto-Escuela, ocuparon posteriormente cátedras de instituto y universidades. Es cierto que la experiencia tuvo dificultades derivadas de la falta de tradición didáctica en la segunda enseñanza o por las prisas de

43 Un ensayo pedagógico, op. cit., pág. 245 
solventar su situación económica por parte de algunos de los aspirantes admitidos, pero no cabe duda de que constituyó un honesto intento por elevar el saber y alma de los docentes como hasta la fecha no se habia hecho. Una experiencia irrepetible que se quebró en 1936 al escribir España una de las páginas más amargas de su historia.

\section{CONCLUSIÓN}

El Instituto-Escuela, como se ha señalado en páginas anteriores, ensayó un modelo de formación inicial para quienes aspirasen a la función docente en la enseñanza secundaria. Su razón de ser fue obvia: el punto de partida de cualquier reforma educativa ha de arrancar de la preparación del profesorado encargado de ponerla en práctica. Si se pensaba experimentar nuevos métodos didácticos, habia que formar futuros docentes, aún entusiastas y permeables, en las nuevas ideas educativas. Era una vieja aspiración del regeneracionismo de finales del siglo $X I X$ y de los hombres próximos a los ideales sostenidos por la Institución Libre de Enseñanza. Idea que se empezó a materializar en 1907 con la creación de la Junta para Ampliación de Estudios e Investigaciones Científicas. Organismo oficial al que se le irán confiando una serie de servicios, entre ellos, el Instituto Escuela, orientados a auxiliar la formación del personal docente e investigador.

La formación del futuro personal docente en el Instituto-Escuela fue una novedad y un hecho singular. Novedad por partida doble: de un lado, era la primera vez que un centro educativo abordaba la preparación cientifica y didáctica de los que iban a ser profesores en el bachillerato; de otro, aún cuando en las Escuelas Normales se ofrecía una cierta preparación didáctica a los futuros maestros con prácticas en las llamadas escuelas anejas, era nuevo el modo con que se planteaba el plan de formación de los aspirantes a ser docentes. Un plan caracterizado por el hecho de que los aspirantes impartian clases, colaboraban con el resto del profesorado en todas las actividades no lectivas del centro, participaban en investigaciones, asistían a clases en la universidad, tenían que aprender dos idiomas y, además, podian ser becados en el extranjero. Rasgos todos que nos hablan del carácter integral con que se abordó la formación de los aspirantes al magisterio secundario: preparación científica ligada a la universidad, una didáctica sustentada en la experiencia y, como complemento, pensión temporal en el extranjero.

También fue una experiencia singular. Más allá de la mera reduplicación que supuso la creación de otros Institutos concebidos a la manera del Instituto-Escuela - tres en Barcelona, uno en Valencia y dos en Andalucía, 
no tuvo imitadores ni continuadores con el tiempo. Ni siquiera durante el período republicano, a pesar de la proximidad afectiva e ideológica entre los dirigentes del primer bienio, los mentores de la Institución Libre de Enseñanza y los que sostuvieron la experiencia del Instituto-Escuela. Es cierto que cabe atribuir a la República el mérito de incorporar los estudios pedagógicos a la universidad, pero no hay ningún parecido entre lo que se ensayó en el Instituto-Escuela y lo que se reguló en enero de 1931 con la creación de la Sección de Pedagogía dentro de las Facultades de Filosofía y Letras, salvo en el ideal institucionista de que todo profesor, con independencia de la asignatura que explique, debe conocer la naturaleza pedagógica de su función. Durante la Segunda República, el Instituto-Escuela siguió desarrollando su programa de formación inicial del profesorado ajeno a las iniciativas legislativas promovidas por el Parlamento y el Gobierno. El único punto de contacto fue el dar acogida como maestras en prácticas, en su sección preparatoria, a alumnas procedentes del cursillo de selección profesional para el ingreso en el ejercicio del magisterio primario.

Tras la guerra civil, tampoco será recogido el discurso y métodos educativos empleados en la formación de los aspirantes al magisterio secundario. Durante la posguerra no existió un plan de formación inicial didáctico para el profesorado de bachillerato. Habrá que esperar a 1970 para ver la aparición de unos Institutos de Ciencias de la Educación que, con escaso entusiasmo, han venido despachando sin control alguno la formación pedagógica de los futuros docentes de la enseñanza secundaria a través de un cursillo. Recientemente se ha tratado de dar una nueva orientación a la formación del profesorado en la recién aprobada Ley General de Ordenación del Sistema Educativo (LOGSE). Heredando en parte el esquema que ya se puso en marcha durante la Segunda República, integra las Escuelas Normales en la universidad y obliga a cursar un año de estudios pedagógicos a todos los que deseen ejercer la función docente en la enseñanza secundaria y bachillerato.

Entonces, ¿por qué una experiencia inicial de formación del profesorado tan rigurosa y completa como la que se proyectó en el Instituto-Escuela quedó relegada al silencio? Tal vez se deba a que generalizar un sistema de formación integral como el desarrollado en el Instituto-Escuela es muy complicado administrativamente, de alto coste económico e imposible de copiar por haber sido pensado y puesto en práctica con una élite de aspirantes con vocación y preparación de base rigurosa. No obstante, y más ahora que estamos en los inicios del proyecto que ha de configurar la formación pedagógica de los futuros enseñantes de secundaria, no estaría de más que se escuchasen los mejores ecos de aquella experiencia que constituyó la formación de los aspirantes al magisterio secundario del Instituto-Escuela. 